\title{
Phosphodiesterase 2A Inhibitor TAK-915 Ameliorates Cognitive Impairments and Social Withdrawal in N-Methyl-D-Aspartate Receptor Antagonist-Induced Rat Models of Schizophrenia ${ }^{\underline{S}}$
}

\author{
Masato Nakashima, Haruka Imada, Eri Shiraishi, Yuki Ito, Noriko Suzuki, Maki Miyamoto, \\ Takahiko Taniguchi, and Hiroki Iwashita
}

Neuroscience Drug Discovery Unit (M.N., H.Im., E.S., Y.I., N.S., T.T., H.Iw.) and Drug Metabolism and Pharmacokinetics Research Laboratories (M.M.), Research, Takeda Pharmaceutical Company Limited, Fujisawa, Japan

Received October 5, 2017; accepted February 5, 2018

\begin{abstract}
The pathophysiology of schizophrenia has been associated with glutamatergic dysfunction. Modulation of the glutamatergic signaling pathway, including $N$-methyl-D-aspartate (NMDA) receptors, can provide a new therapeutic target for schizophrenia. Phosphodiesterase 2A (PDE2A) is highly expressed in the forebrain, and is a dual substrate enzyme that hydrolyzes both CAMP and cGMP, which play pivotal roles as intracellular second messengers downstream of NMDA receptors. Here we characterize the in vivo pharmacological profile of a selective and brain-penetrant PDE2A inhibitor, ( $N$-\{(1S)-1-[3-fluoro-4(trifluoromethoxy)phenyl]-2-methoxyethyl\}-7-methoxy-2-oxo2,3-dihydropyrido[2,3-b]pyrazine-4(1H)-carboxamide) (TAK-915) as a novel treatment of schizophrenia. Oral administration of TAK-915 at 3 and $10 \mathrm{mg} / \mathrm{kg}$ significantly increased cGMP levels in the frontal cortex, hippocampus, and striatum of rats. TAK-915 at
\end{abstract}

\section{Introduction}

Schizophrenia is a severe psychiatric disorder characterized by three domains: positive symptoms, negative symptoms, and cognitive impairments. Current antipsychotic medications are effective in managing positive symptoms but are limited in their ability to alleviate cognitive impairments and negative symptoms. Cognitive impairments are present at the onset of illness and persistent through the course of the disease, and appear to be strong predictors of functional outcome (Shamsi et al., 2011; Torgalsboen et al., 2015). Negative symptoms range from diminished expression, such as blunted affect and poverty of speech, to motivational deficits characterized by avolition, anhedonia, and social withdrawal (Messinger et al., 2011; Foussias et al., 2014).

This work was supported by Takeda Pharmaceutical Company Limited. All authors were employees of Takeda Pharmaceutical Company Limited.

https://doi.org/10.1124/jpet.117.245506.

S This article has supplemental material available at jpet.aspetjournals.org.
$10 \mathrm{mg} / \mathrm{kg}$ significantly upregulated the phosphorylation of $\alpha$-amino3-hydroxy-5-methylisoxazole-4-proprionic acid receptor subunit GluR1 in the rat hippocampus. TAK-915 at 3 and $10 \mathrm{mg} / \mathrm{kg}$ significantly attenuated episodic memory deficits induced by the NMDA receptor antagonist (+)-MK-801 hydrogen maleate (MK-801) in the rat passive avoidance test. TAK-915 at $10 \mathrm{mg} / \mathrm{kg}$ significantly attenuated working memory deficits induced by MK-801 in the rat radial arm maze test. Additionally, TAK-915 at $10 \mathrm{mg} / \mathrm{kg}$ prevented subchronic phencyclidine-induced social withdrawal in social interaction in rats. In contrast, TAK-915 did not produce antipsychotic-like activity; TAK-915 had little effect on MK-801- or methamphetamine-induced hyperlocomotion in rats. These results suggest that TAK-915 has a potential to ameliorate cognitive impairments and social withdrawal in schizophrenia.

ABBREVIATIONS: AMPA, ( \pm )- $\alpha$-amino-3-hydroxy-5-methylisoxasole-4-proprionic acid; BAY 60-7550, 2-[(3,4-dimethoxyphenyl)methyl]-7[(2R,3R)-2-hydroxy-6-phenylhexan-3-yl]-5-methyl-1H-imidazo[5,1-f][1,2,4]triazin-4-one; Enk, enkephalin; GAPDH, glyceraldehyde-3-phosphate dehydrogenase; METH, methamphetamine hydrochloride; MK-801, (+)-MK-801 hydrogen maleate; MP-10, 2-[4-(1-methyl-4-pyridin-4-yl-1Hpyrazol-3-yl)-phenoxymethyl]-quinoline succinate; MSNs, medium spiny neurons; NMDA, N-methyl-D-aspartate; NO, nitric oxide; PCP, phencyclidine; PDE, phosphodiesterase; PDE2A, phosphodiesterase 2A; pGluR1, phosphorylation of AMPA receptor subunit at serine 845; PKA, protein kinase A; PKG, protein kinase G; PO, by mouth; SD, Sprague-Dawley; SP, substance P; TAK-915, N-\{(1S)-1-[3-fluoro-4(trifluoromethoxy)phenyl]-2-methoxyethyl\}-7-methoxy-2-oxo-2,3-dihydropyrido[2,3-b]pyrazine-4(1H)-carboxamide. 
donor sodium nitroprusside has shown a rapid improvement in multiple symptoms of schizophrenia (Hallak et al., 2013). These findings suggest that the modulation of glutamatergic transmission, which includes NMDA receptor/NO/cGMP pathway, can provide a new therapy for schizophrenia.

Phosphodiesterase 2A (PDE2A) is a dual substrate enzyme that hydrolyzes both cAMP and cGMP. PDE2A is abundant in the brain relative to peripheral tissues, and highly expressed in the forebrain, including the frontal cortex, hippocampus, and striatum, which are relevant to cognition (Stephenson et al., 2009, 2012). PDE2A is localized in axons and nerve terminals of principal neurons, suggesting that PDE2A plays an important role in the modulation of cyclic nucleotidemediated signal transduction, synaptic neurotransmission, and plasticity in the forebrain. Thus, the role of PDE2A on cognition under physiologic and pathologic conditions has been investigated. Some PDE2A inhibitors, such as BAY 60-7550, have enhanced recognition memory in the novel object recognition task in rodents (Boess et al., 2004; Rutten et al., 2007; Reneerkens et al., 2013; Bollen et al., 2014, 2015; Redrobe et al., 2014; Lueptow et al., 2016). However, these findings have not fully shown the relationship between brainPDE2A inhibition and procognitive activities in rodents. Most of the studies using PDE2A inhibitors lack adequate evidence in terms of pharmacokinetics and pharmacodynamics. For example, there are no reports that investigate brain cyclic nucleotide levels after BAY-60-7550 administration. This compound does not show sufficient brain-penetrant properties in rodents after oral administration (Reneerkens et al., 2013). Therefore, a PDE2A inhibitor with better pharmacokinetic profiles would be required to elucidate the role of PDE2A inhibition in the brain and clarify the relationship between brain cyclic nucleotide levels and behavioral outcomes.

We recently discovered a potent and selective PDE2A inhibitor, TAK-915 (Mikami et al., 2017). TAK-915 inhibited human PDE2A3 enzyme activities with a 50\% inhibitory concentration of $0.61 \mathrm{nmol} / \mathrm{l}$, which exhibited more than 4100 fold selectivity against other phosphodiesterase (PDE) family members. In autoradiography studies in rodents in vitro, $\left[{ }^{3} \mathrm{H}\right]$ TAK-915 was accumulated in the frontal cortex, hippocampus, and striatum in rodents (Ito Y, Imada H, Obayashi Y, Kasahara M, Hattori M, Miyamoto M, Mikami S, Taniguchi T, and Iwashita $\mathrm{H}$, manuscript in preparation), where PDE2A expression levels are high (Stephenson et al., 2009, 2012). This selective accumulation of $\left[{ }^{3} \mathrm{H}\right] \mathrm{TAK}-915$ was not observed in brain slices from Pde2a conditional knockout mice (Ito Y, Imada H, Obayashi Y, Kasahara M, Hattori M, Miyamoto M, Mikami $\mathrm{S}$, Taniguchi $\mathrm{T}$, and Iwashita $\mathrm{H}$, manuscript in preparation). These findings indicate that TAK-915 selectively binds to a native PDE2A under physiologic conditions.

In this report, we show the in vivo pharmacological profile of a selective and brain-penetrant PDE2A inhibitor, TAK-915, as a potential treatment of schizophrenia. First, to examine whether TAK-915 acts as a PDE2A inhibitor in vivo, we measured cyclic nucleotide contents and their downstream signaling in the brain. Second, we characterized the procognitive properties of TAK-915 in NMDA receptor antagonistinduced deficit models. Third, to investigate the potential of TAK-915 on social withdrawal, we evaluated social interaction in a subchronic PCP model. Finally, we performed psychostimulant-induced hyperlocomotion tests to predict the effect of TAK-915 on antipsychotic-like activity.

\section{Materials and Methods}

Animals. The care and use of the animals and the experimental procedures performed at Takeda Pharmaceutical Company Limited (Fujisawa, Japan) were approved by the Experimental Animal Care and Use Committee of Takeda Pharmaceutical Company Limited. Experiments performed at Biotrial (Rennes, France) were approved by the Biotrial Ethical Committee. Specific details of strain and species are given within each section. The animals were housed in groups of two to four per cage under a 12-hour light-dark cycle (lights on at 7:00 $\mathrm{AM})$ with ad libitum food and water. After at least a 1-week habituation period, the animals were used for the experiment.

Drugs. TAK-915 ( $N$-\{(1S)-1-[3-fluoro-4-(trifluoromethoxy)phenyl]2-methoxyethyl\}-7-methoxy-2-oxo-2,3-dihydropyrido[2,3-b]pyrazine4(1H)-carboxamide) and MP-10 succinate (MP-10, 2-[4-(1-methyl-4pyridin-4-yl- $1 H$-pyrazol-3-yl)-phenoxymethyl]-quinoline succinate) were synthesized at Takeda Pharmaceutical Company Limited (Grauer et al., 2009; Verhoest et al., 2009; Mikami et al., 2017). TAK-915 and MP-10 were suspended in $0.5 \%(\mathrm{w} / \mathrm{v})$ methylcellulose in distilled water and administered orally (p.o.). Methamphetamine hydrochloride (METH; Dainippon Sumitomo Pharma Co. Ltd., Osaka, Japan) and (+)-MK-801 hydrogen maleate (MK-801; Sigma-Aldrich, St. Louis, MO) were dissolved in saline, and were administered subcutaneously (s.c.). Phencyclidine hydrochloride (PCP; Sigma Chemical Co., Saint Quentin Fallavier, France) was dissolved in saline, and was administered intraperitoneally (i.p.). The dosages of compounds were expressed as salt forms. The volume of administration was $2 \mathrm{ml} / \mathrm{kg}$ for p.o. and s.c., $5 \mathrm{ml} / \mathrm{kg}$ for i.p.

Pharmacokinetics Study. Eight-week-old male Long-Evans rats (Japan SLC Inc., Hamamatsu, Japan) and male SpragueDawley (SD) rats (Charles River Laboratories Japan, Inc., Yokohama, Japan) were used for sample collection. Blood and brain tissues were collected at $0.5,1$, or 2 hours after administration of TAK-915. The plasma or brain-homogenate samples were deproteinized with acetonitrile containing an internal standard and then centrifuged. The supernatant was diluted with solvents consisting of $10 \mathrm{mM}$ ammonium acetate-acetonitrile-formic acid and centrifuged again. An LC-MS/MS system (API5000 or QTRAP5500; AB Sciex, Foster City, CA) was used to measure TAK-915 concentrations in the supernatant.

In Vivo Measurement of Cyclic Nucleotide Contents. This assay was performed as previously described (Suzuki et al., 2015, 2016) with some modifications. Nine-week-old male Long-Evans rats were euthanized using a microwave irradiation system (MMW-05; Muromachi Kikai Co. Ltd., Tokyo, Japan) 2 hours following oral administration of vehicle or TAK-915 $(1,3$, or $10 \mathrm{mg} / \mathrm{kg})$. Brain tissues were sampled, immediately frozen on dry ice, and stored at $-80^{\circ} \mathrm{C}$ until use. To measure cyclic nucleotide contents, microwaved brain tissues were isolated and then homogenized in $0.5 \mathrm{~N} \mathrm{HCl}$ followed by centrifugation. Cyclic nucleotide concentrations in supernatant were measured using enzyme immunoassay kits (Cayman Chemical Company, Ann Arbor, MI) in accordance with the manufacturer's protocol. Values were expressed as picomoles per milligram tissue weight.

In Vivo Measurement of Protein Phosphorylation. Sevenweek-old male Long-Evans rats were used for collecting the brain tissues. The hippocampus was immediately sampled 2 hours after oral administration of vehicle or TAK-915 $(1,3$, or $10 \mathrm{mg} / \mathrm{kg})$ and put into $1.5-\mathrm{ml}$ tubes. Samples were rapidly frozen in liquid nitrogen, and stored at $-80^{\circ} \mathrm{C}$ until use. Whole hippocampus tissues were homogenized in ice-cold cell extraction buffer (Invitrogen/Thermo Fisher Scientific, Carlsbad, CA) with protease inhibitor cocktail (SigmaAldrich) and phosphatase inhibitor cocktail (Thermo Fisher Scientific, Waltham, MA). After clarification by centrifugation, the supernatant fraction was collected and boiled in sample buffer solution with 3-mercapto-1,2-propanediol (Wako, Osaka, Japan). The protein content $(0.5 \mu \mathrm{g})$ of each sample was loaded onto $7.5 \%-15 \%$ SDS-PAGE gels (DRC, Tokyo, Japan). After electrophoresis, the proteins were transferred to polyvinylidene fluoride membranes. Total protein levels and phosphorylation of ( \pm )- $\alpha$-amino-3-hydroxy-5-methylisoxasole-4-proprionic 
TABLE 1

Plasma and brain concentrations of TAK-915 in rats $0.5,1$, and 2 hours following the administration of TAK-915 (1, 3, or $10 \mathrm{mg} / \mathrm{kg}$, p.o.)

Data are expressed as mean \pm S.D., $n=3$ per each group.

\begin{tabular}{ccccc}
\hline Rat Strain & Dose & Time & Plasma Concentration & Brain Concentration \\
\hline Long-Evans & $m g / k g, p . o$. & $h$ & $\mu g / m l$ & $\mu g / g$ \\
& 1 & 0.5 & $0.033 \pm 0.002$ & $0.028 \pm 0.003$ \\
& & 1 & $0.038 \pm 0.025$ & $0.037 \pm 0.019$ \\
& 3 & 2 & $0.023 \pm 0.013$ & $0.030 \pm 0.021$ \\
& & 0.5 & $0.065 \pm 0.022$ & $0.063 \pm 0.017$ \\
& 10 & 2 & $0.098 \pm 0.053$ & $0.114 \pm 0.055$ \\
Sprague-Dawley & & $0.121 \pm 0.013$ & $0.160 \pm 0.016$ \\
& & 1 & $0.227 \pm 0.067$ & $0.192 \pm 0.042$ \\
& 10 & 0.5 & $0.282 \pm 0.152$ & $0.267 \pm 0.120$ \\
& & 1 & $0.119 \pm 0.040$ & $0.331 \pm 0.095$ \\
& & 2 & $0.141 \pm 0.025$ & $0.090 \pm 0.051$ \\
& & $0.272 \pm 0.099$ & $0.134 \pm 0.038$ \\
& & & $0.280 \pm 0.114$ \\
\hline
\end{tabular}

acid (AMPA) receptor subunit at serine 845 (pGluR1) proteins were probed by immunoblotting with anti-total glutamate receptor subunit 1 (GluR1) antibody (diluted 1:5000; MilliporeSigma, Temecula, CA) and anti-pGluR1 (diluted 1:2000; PhosphoSolutions, Aurora, CO), and were visualized with horseradish peroxidase-conjugated second antibodies (diluted 1:5000; GE Healthcare UK Ltd., Buckinghamshire, UK) followed by ECL prime Western blotting detection reagents (GE Healthcare UK Ltd.). The membranes were scanned on a luminoimage analyzer, ImageQuant LAS4000 (Fujifilm, Tokyo, Japan). The amounts of total and pGluR1 proteins were quantified by measuring the density of blots using ImageQuant TL software (Fujifilm). The band densities of pGluR1 were normalized by those of total GluR1.

Step-Through Passive Avoidance Task. This task was conducted using 7- to 8-week-old male Long-Evans rats as previously described (Mikami et al., 2017). The task was carried out in an apparatus consisting of an illuminated ("light") compartment $(25 \times$ $10 \times 25 \mathrm{~cm})$ connected to a non-illuminated ("dark") compartment $(30 \times 30 \times 30 \mathrm{~cm})$ by a guillotine door $(8 \times 8 \mathrm{~cm})$ (Brain Science idea, Osaka, Japan). In a habituation trial, each animal was gently placed in the light compartment. After 30 seconds, the guillotine door was opened and the rat was allowed to enter the dark compartment. Once the animal entered the dark compartment with all four paws, the door was closed. The animal was allowed to remain in the dark compartment for 30 seconds before being taken to its home cage. An acquisition trial was conducted $4-6$ hours after the habituation trial. The rat was put into the light compartment, and the guillotine door was opened. Once the rat crossed into the dark compartment with all four paws, the door was closed and an electric shock (0.5 mA, 3-second) was delivered from the grid floor. After 30 seconds, the rat was removed from the dark compartment, and then returned to its home cage. One day after the acquisition trial, a retention test was performed to evaluate memory. After each rat was again put into the light compartment for 30 seconds, the door was opened. The retention test was terminated when the rat entered the dark compartment or remained in the light compartment for 300 seconds. During the retention trials, no electric shock was delivered from the grid floor. The time between the door being opened and the rat entering the dark compartment was defined as latency time. The maximum latency time for which the rat did not enter the dark compartment was 300 seconds. Vehicle or TAK-915 (1, 3 , or $10 \mathrm{mg} / \mathrm{kg}$, p.o.) was administered 2 hours prior, and saline or MK-801 $(0.1 \mathrm{mg} / \mathrm{kg}$, s.c. $)$ was administered 30 minutes prior to the acquisition trial.

Radial Arm Maze Task. This task was assessed using 9-weekold male Long-Evans rats as previously described (Shiraishi et al., 2016; Nishiyama et al., 2017). An eight-arm radial maze (with arms $50 \times 10 \times 40 \mathrm{~cm}$ ) was mounted on a platform elevated $50 \mathrm{~cm}$ above the floor. Animals were fasted for 1 day before habituation of the maze. During the experimental period after the first day of habituation, animals were food-restricted to $85 \%-90 \%$ of free-feeding body weight for training. Reinforcement consisted of three food pellets (Dustless Precision Pellets, 45 mg; Bio-Serv Inc., Frenchtown, NJ), which were placed in a food cup at the end of each arm. Habituation: On the first day, three rats were placed in the maze and allowed to freely explore for 8 minutes and retrieve the food pellets, which were placed near the entrance and at the mid-point of each arm. On the second day, a single rat was allowed to explore for 5 minutes and retrieve the pellets, which were then placed at the mid-point and in the food cup at the end of each arm. Training: From the third day, reinforcement was placed in the food cup at the end of each arm. Each rat was allowed to explore until 5 minutes had elapsed, or the rat completed one entry in each arm. Entry into an arm previously chosen, and failure to get the pellets were counted as errors. Rats were trained until they achieved a criterion of $\leq 2$ errors for 2 consecutive days. Vehicle or TAK-915 ( 1 or $10 \mathrm{mg} / \mathrm{kg}$, p.o.) was administered 2 hours, and saline or MK- $801(0.08 \mathrm{mg} / \mathrm{kg}$, s.c. $)$ was administered 30 minutes prior to the test.

Social Interaction Test. This experiment was carried out at Biotrial using male Long-Evans rats (JANVIER LABS, Saint Berthevin, France) as previously described (Cayre et al., 2016). The experimental arena was a square wooden box $(90 \times 90 \times 40 \mathrm{~cm})$ painted dark blue, with black-painted squares $(15 \times 15 \mathrm{~cm})$. The arena was cleaned using water between each trial to avoid odor trails left by rats. The arena was placed in a dark room illuminated only by halogen lamps oriented toward the ceiling, which provided uniform dim light in the box. The day before the test, rats were placed in the box and allowed to habituate for 10 minutes. On the experimental day, treated animals were placed with an unfamiliar animal in the experimental arena for a 10-minute experimental session to allow them to interact freely. The experimenter then scored the time spent in social interaction for the treated rat. For each treated rat, the total amount of time spent in active social behavior was recorded during the 10-minute session. Active social behaviors were defined as sniffing, grooming, kicking, following, mounting, jumping on, boxing, wrestling, and crawling. The experimenter scoring the behavior was not aware of the animal treatment. Saline or PCP $(5 \mathrm{mg} / \mathrm{kg}$, i.p.) was administered twice daily (morning and afternoon) from days 1 to 7 . During the wash-out period from days 8 to 15 , animals were housed in their home cages without any treatment. On day 15, habituation was conducted. On day 16, vehicle or TAK-915 (3 or $10 \mathrm{mg} / \mathrm{kg}$, p.o.) was administered 2 hours before testing.

Hyperlocomotion Test. This test was assessed using 8-week-old male SD rats as previously described (Suzuki et al., 2015, 2016). A SUPERMEX spontaneous motor analyzer (Muromachi Kikai Co., Ltd., Tokyo, Japan) was used to measure locomotion. Rats were placed in locomotor chambers $(24 \times 37 \times 30 \mathrm{~cm})$ for more than 60 minutes for habituation. Thereafter, rats were injected with either 

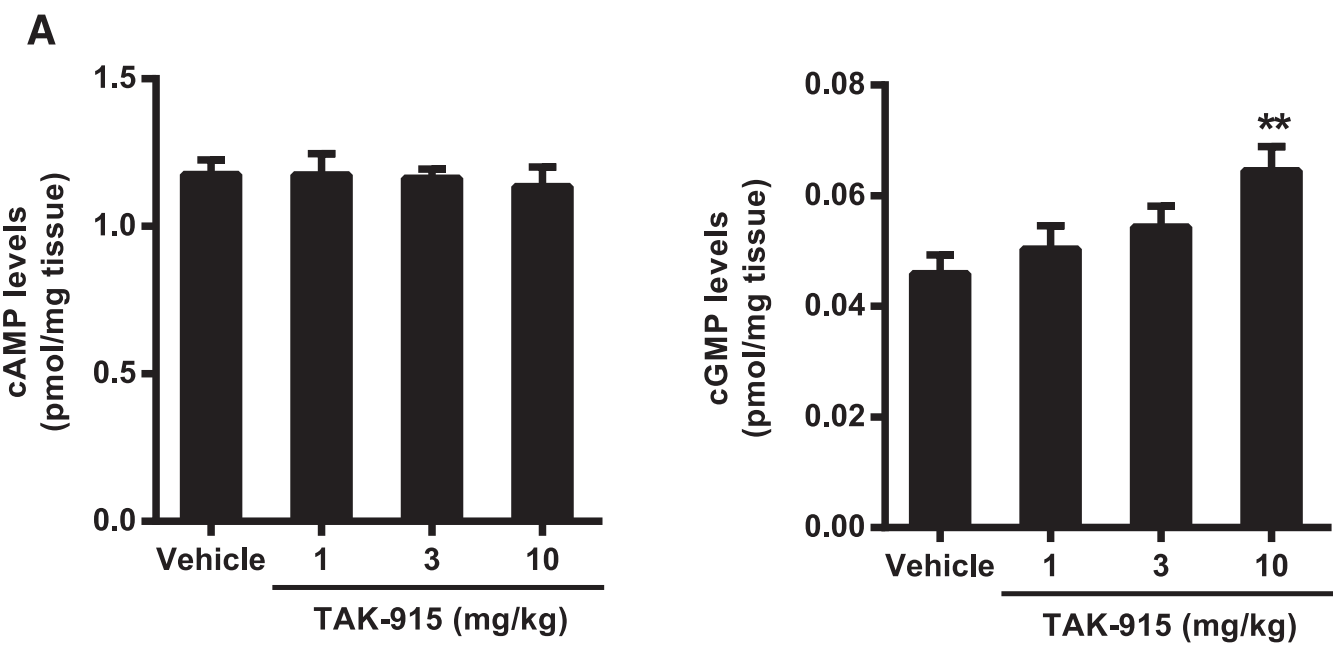

B
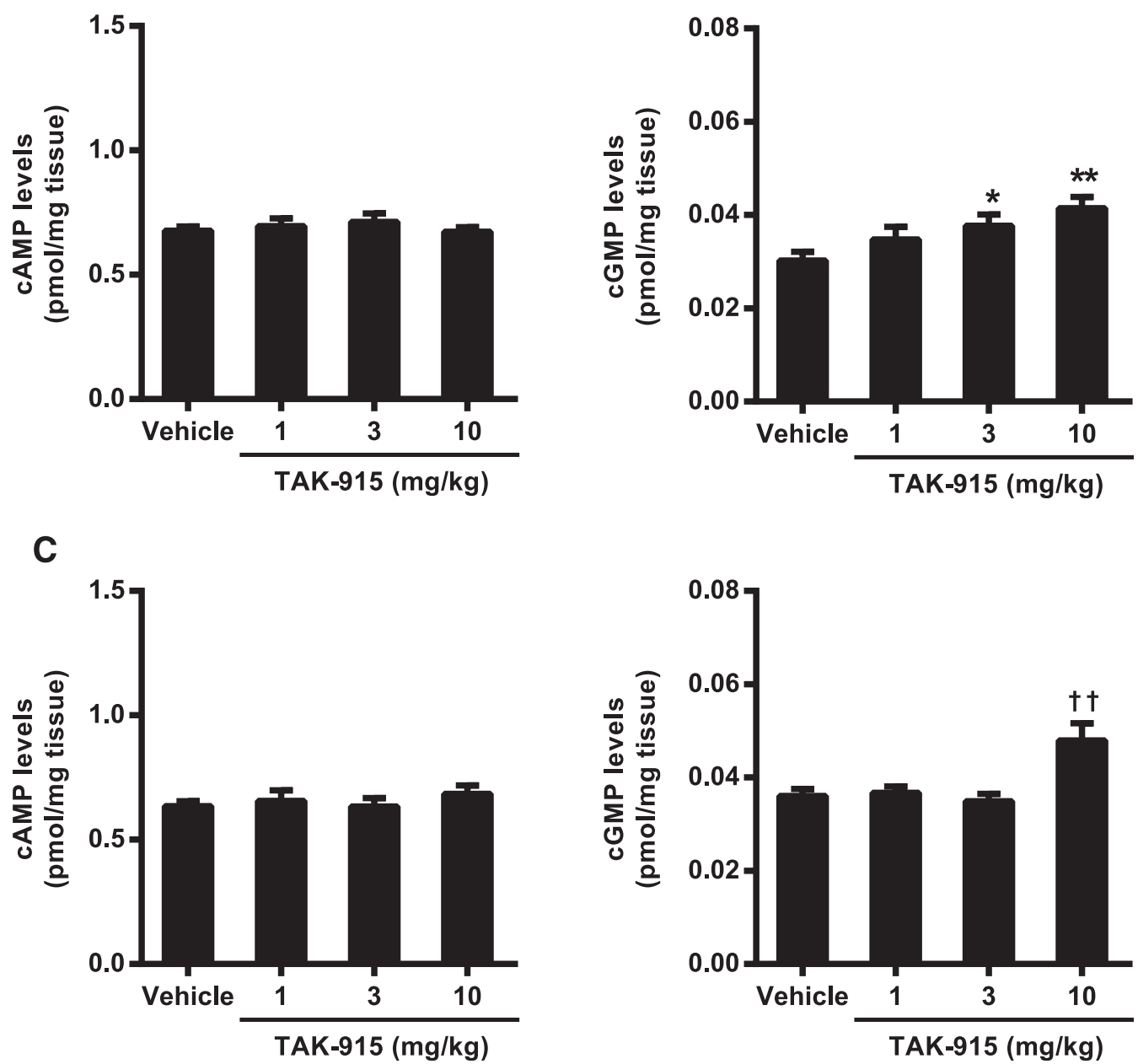

Fig. 1. Effects of TAK-915 on cAMP and cGMP levels in the frontal cortex, hippocampus, and striatum in rats. Vehicle or TAK-915 (1,3, or $10 \mathrm{mg} / \mathrm{kg}$, p.o.) was administered 2 hours before sampling. Cyclic nucleotide contents in the frontal cortex (A), hippocampus (B), and striatum (C) were measured using enzyme immunoassay kits. Data are expressed as mean + S.E.M., $n=9$ per each group. $* P \leq 0.05$; $* * P \leq 0.01$ (vs. vehicle by two-tailed Williams' test), ${ }^{\dagger} P \leq 0.01$ (vs. vehicle by two-tailed Shirley-Williams' test).

vehicle or TAK-915 (1, 3, or $10 \mathrm{mg} / \mathrm{kg}$, p.o.) and then quickly returned to the chamber. After 2 hours, rats were again taken out of the chambers and injected with either saline, MK-801 (0.3 mg/kg, s.c.), or METH $(0.5 \mathrm{mg} / \mathrm{kg}$, s.c.) and then quickly returned to the chamber. Activity counts were recorded every 1 minute during the 2 hours after administration of psychostimulant.
Gene Expression Assay. This assay was conducted as previously described (Suzuki et al., 2015, 2016). Seven-week-old male SD rats were euthanized 3 hours after oral treatment with vehicle, TAK-915 (10 or $100 \mathrm{mg} / \mathrm{kg})$, or MP-10 (30 mg/kg). Striatum was collected and frozen on dry ice immediately and then stored $-80^{\circ} \mathrm{C}$ until use. Total RNA from the striatum was extracted using Isogen (Nippon Gene Co., 
A

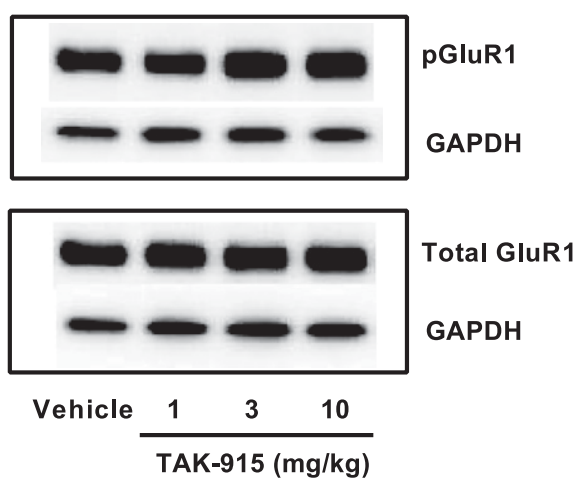

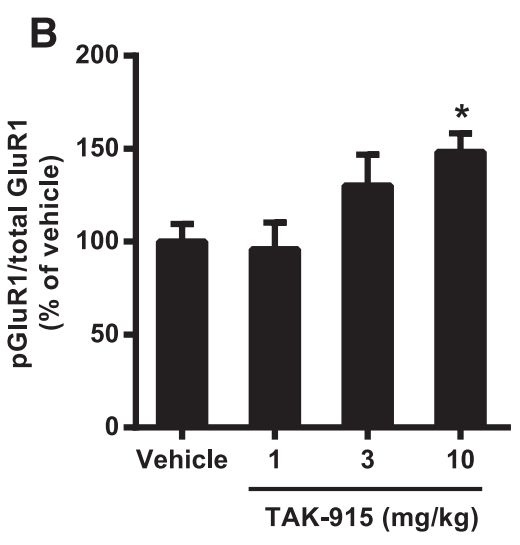

Fig. 2. Effects of TAK-915 on pGluR1 levels in the rat hippocampus. Vehicle or TAK-915 (1, 3, or $10 \mathrm{mg} / \mathrm{kg}$, p.o.) was administered 2 hours before collecting the rat hippocampus. (A) Representative blots were probed with primary antibodies for pGluR1, GAPDH, and total GluR1. (B) The intensity of the pGluR1 band for each sample was normalized to the corresponding GluR1 band density. Data are expressed as mean + S.E.M., $n=6$ per each group. $* P \leq 0.05$ (vs. vehicle by twotailed Williams' test).
Ltd., Toyama, Japan) and an RNeasy Mini Kit (Qiagen, Hilden, Germany) according to the manufacturer's protocol. The RNA was reverse-transcribed to cDNA using High-capacity cDNA Reverse Transcription Kit (Life Technologies/Thermo Fisher Scientific). Realtime quantitative polymerase chain reaction expression analysis was conducted using TaqMan reagents (Eurogentec, Seraing, Belgium) and ABI PRISM 7900HT sequence detection system (Life Technologies). In accordance with the manufacturer's instruction, quantities of RNA were normalized using glyceraldehyde-3-phosphate dehydrogenase (GAPDH) TaqMan probes. The rat enkephalin (Enk) analysis was conducted using the following primers: forward primer, $5^{\prime}$ GGACTGCGCTAAATGCAGCTA-3'; reverse primer, 5'-GTGTGCATGCCAGGAAGTTG-3'; TaqMan probe (MGB probe), 5'-CGCCTGGTACGTCCCGGCG-3'. The rat substance $\mathrm{P}$ (SP) was conducted using the following primers: forward primer, 5'-CGCAAAATCCAACATGAAAATC-3'; reverse primer, 5'-GCAAACAGTTGAGTGGAAACGA-3'; TaqMan probe (MGB probe), 5'-CGTGGCGGTGGCGGTCTTTTT-3'. The rat GAPDH analysis was conducted using the following primers: forward primer, 5' -TGCCAAGTATGATGACATCAAGAAG-3'; reverse primer, 5' -AGCCCAGGATGCCCTTTAGT-3'; TaqMan probe (MGB probe), 5'-TGGTGAAGCAGGCGGCCGAG-3'.

Statistical Analysis. The Aspin-Welch test (for nonhomogeneous data) or Student's $t$ test (for homogeneous data) was used for pairwise group comparison. In dose-response experiments, homogeneity of variances was verified using Bartlett's test, and then two-tailed Williams' test (for parametric data) or two-tailed Shirley-Williams test (for non-parametric data) was conducted. In the step-through passive avoidance test, two-tailed Wilcoxon's test was conducted. Value of $P \leq 0.05$ was considered significant. The materials and methods for supplemental figures (Supplemental Fig. 1-4) were described in Supplementation Experimental Procedure.

\section{Results}

Effects of TAK-915 on cAMP and cGMP Levels in the Frontal Cortex, Hippocampus, and Striatum in Rats. Two hours after oral administration of TAK-915, the concentration of TAK-915 in the brain of Long-Evans rats was $0.030 \pm 0.021 \mu \mathrm{g} / \mathrm{g}$ at $1 \mathrm{mg} / \mathrm{kg}, 0.160 \pm 0.016 \mu \mathrm{g} / \mathrm{g}$ at $3 \mathrm{mg} / \mathrm{kg}$, and $0.331 \pm 0.095 \mu \mathrm{g} / \mathrm{g}$ at $10 \mathrm{mg} / \mathrm{kg}$ (Table 1). The brain concentration of TAK-915 dose dependently increased, and the exposure was sustained for at least up to 2 hours after dosing in rats. To assess the effect of PDE2A inhibition by TAK-915 in the brain, we measured cyclic nucleotide contents in the frontal cortex, hippocampus, and striatum in rats at 2 hours after oral administration. Oral administration of TAK915 dose dependently increased cGMP levels in these brain regions. Significant increase in cGMP levels was observed at $10 \mathrm{mg} / \mathrm{kg}$ of TAK-915 in the frontal cortex $(0.063 \pm 0.004$ $\mathrm{pmol} / \mathrm{mg}, P \leq 0.01$; Fig. $1 \mathrm{~A}$ ), at 3 and $10 \mathrm{mg} / \mathrm{kg}$ in the hippocampus $(0.037 \pm 0.002, P \leq 0.05$, at $3 \mathrm{mg} / \mathrm{kg} ; 0.042 \pm$ $0.002 \mathrm{pmol} / \mathrm{mg}, P \leq 0.01$, at $10 \mathrm{mg} / \mathrm{kg}$; Fig. $1 \mathrm{~B}$ ), and at $10 \mathrm{mg} / \mathrm{kg}$ in the striatum $(0.047 \pm 0.003 \mathrm{pmol} / \mathrm{mg}, P \leq 0.01$; Fig. 1C). On the other hand, TAK-915 did not affect cAMP levels in the rat brain even at $10 \mathrm{mg} / \mathrm{kg}$, p.o. In addition, TAK915 at $30 \mathrm{mg} / \mathrm{kg}$ increased cGMP levels not only in the brain parenchyma but also in the cerebrospinal fluid (CSF), and the time-dependent changes of cGMP levels in brain and CSF accorded well with the changes of pharmacokinetics of TAK915 (Supplemental Fig. 1).

Effects of TAK-915 on pGluR1 Levels in the Rat Hippocampus. An increase in intracellular cyclic nucleotide levels induces the activation of protein kinase A (PKA) and protein kinase $\mathrm{G}(\mathrm{PKG})$ and results in upregulation of pGluR1 level (Wang et al., 2005; Serulle et al., 2007, 2008). To assess the effect of TAK-915 on the downstream pathway of cyclic nucleotide signaling, we investigated the phosphorylation levels of GluR1 in the hippocampus following oral administration of TAK-915 at 1, 3, and $10 \mathrm{mg} / \mathrm{kg}$. As shown in Fig. 2, TAK-915 dose dependently increased pGluR1 in the rat hippocampus, in the same dose range of TAK-915 that increased hippocampal cGMP levels; the relative phosphorylation levels at 1,3 , and $10 \mathrm{mg} / \mathrm{kg}$ of TAK-915 were $96 \% \pm 14 \%$, $130 \% \pm 17 \%$, and $148 \% \pm 10 \%$, respectively. Significant increase in the pGluR1 levels was observed at $10 \mathrm{mg} / \mathrm{kg}$, p.o. $(P \leq 0.05$; Fig. 2B).

Effects of TAK-915 on MK-801-Induced Episodic Memory Deficits in the Step-Through Passive Avoidance Task in Rats. Among several cognitive domains, patients with schizophrenia have shown larger impairments in episodic memory (Schaefer et al., 2013). The NMDA receptor antagonist MK-801 has produced schizophrenia-like symptoms including episodic memory deficits in rodents (Neill et al., 2010; van der Staay et al., 2011). To assess the effects of TAK-915 on the episodic memory deficits induced by the NMDA receptor antagonist, we performed the passive avoidance task in MK-801-treated rats. As shown in Fig. 3, subcutaneous treatment with MK-801 at $0.1 \mathrm{mg} / \mathrm{kg}$ significantly decreased the avoidance time in retention test compared with saline $(P \leq 0.01)$. TAK-915 at 3 and $10 \mathrm{mg} / \mathrm{kg}$ significantly attenuated the MK-801-induced deficits in the avoidance time $(P \leq 0.01$ at $3 \mathrm{mg} / \mathrm{kg}$; Fig. 3B, $P \leq 0.05$ at $10 \mathrm{mg} / \mathrm{kg}$; Fig. 3C).

Effects of TAK-915 on MK-801-Induced Spatial Working Memory Deficits in Radial Arm Maze Task in Rats. To evaluate the effect of TAK-915 on spatial working 

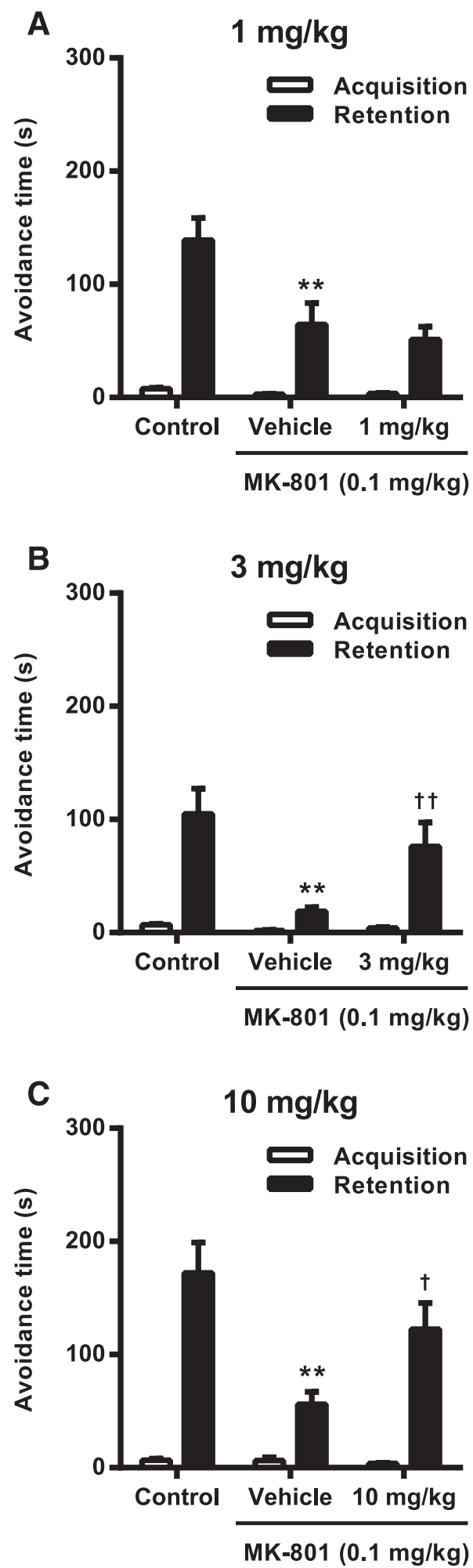

Fig. 3. Effects of TAK-915 on MK-801-induced episodic memory deficits in the step-through passive avoidance task in rats. Vehicle or TAK-915 [(A) $1 \mathrm{mg} / \mathrm{kg}$, p.o., (B) $3 \mathrm{mg} / \mathrm{kg}$, p.o., (C) $10 \mathrm{mg} / \mathrm{kg}$, p.o.] was administered 2 hours prior, and saline or MK- $801(0.1 \mathrm{mg} / \mathrm{kg}$, s.c. $)$ was administered 30 minutes prior to the acquisition trial. The latency to dark compartment was measured until the rat entered the dark compartment with all four paws or remained in the illuminated compartment for 300 seconds. One day after acquisition trial, retention trial was conducted. Data are expressed as mean + S.E.M., $n=19$ for control group in the experiment of $3 \mathrm{mg} / \mathrm{kg}, n=20$ for other groups. $* * P \leq 0.01$ (vs. control by two-tailed memory deficits, which are observed in patients with schizophrenia (Piskulic et al., 2007), we performed the radial arm maze task in rats with an MK-801-induced deficit. In the control group, all pellets in the eight arms were effectively consumed within two errors (Fig. 4). Treatment of MK-801 at $0.08 \mathrm{mg} / \mathrm{kg}$, s.c., significantly increased the number of errors (5.6 $\pm 0.8, P \leq 0.01$; Fig. 4). Pretreatment with TAK-915 at $10 \mathrm{mg} / \mathrm{kg}$, p.o. significantly reduced the number of errors induced by MK-801 (3.4 $\pm 0.5, P \leq 0.05$; Fig. 4).

Effects of TAK-915 on Subchronic PhencyclidineInduced Social Withdrawal in the Social Interaction Test in Rats. Rodents treated subchronically with PCP have been used for investigating social withdrawal, a key subdomain of negative symptoms (Wilson and Koenig, 2014). To assess the potential of TAK-915 for the treatment of negative symptoms, we evaluated the effect of TAK-915 on subchronic PCP-induced social withdrawal by using social interaction test in rats. Time spent in social interactions was significantly decreased in subchronic PCP-treated rats (30 \pm 10 seconds) compared with control group rats $(83 \pm 10$ seconds $)(P \leq 0.01$, Fig. 5). TAK-915 (3 or $10 \mathrm{mg} / \mathrm{kg}$, p.o.) dose dependently attenuated subchronic PCP-induced deficits in social interaction test $(49 \pm 6$ seconds at $3 \mathrm{mg} / \mathrm{kg}, 72 \pm 9$ seconds at $10 \mathrm{mg} / \mathrm{kg}$; Fig. 5). Significant effect in this test was observed at $10 \mathrm{mg} / \mathrm{kg}$, p.o. $(P \leq 0.05$; Fig. 5$)$.

Effects of TAK-915 on MK-801- or METH-Induced Hyperlocomotion, and on Activation of Direct and Indirect Pathway Medium Spiny Neurons in Rats. The MK-801- or METH-induced hyperlocomotion test has been commonly used as an animal model for positive symptoms in schizophrenia (Andine et al., 1999; Jones et al., 2011). Current antipsychotics, such as aripiprazole, olanzapine, and haloperidol, have attenuated psychostimulant-induced hyperlocomotion (Suzuki et al., 2015). As shown in Fig. 6A, TAK-915 did not affect the MK-801-induced hyperlocomotion in rats even at $10 \mathrm{mg} / \mathrm{kg}$. Likewise, TAK-915 did not suppress the METHinduced hyperlocomotion in rats (Fig. 6B). Activation of the indirect pathway medium spiny neurons (MSNs) by the blockade of dopamine $\mathrm{D}_{2}$ receptors is thought to be a common mechanism of action of current antipsychotics (Kapur and Mamo, 2003; Agid et al., 2008; Kehler and Nielsen, 2011; Suzuki et al., 2015). To evaluate the effect of TAK-915 on the activation of direct and indirect pathway MSNs, we measured striatal mRNA expression levels of SP (a direct pathway marker) and Enk (an indirect pathway marker). MP-10, developed by Pfizer (New York, NY), has been reported to be a potent and selective PDE10A inhibitor (Grauer et al., 2009; Verhoest et al., 2009). As a positive control, we used MP-10, which has been reported to activate both direct and indirect pathway MSNs (Suzuki et al., 2016). As previously reported, MP-10 at $30 \mathrm{mg} / \mathrm{kg}$ significantly increased the expression of both SP and Enk mRNA $(P \leq 0.01$ for SP and $P \leq 0.01$ for Enk; Fig. 6C). In contrast, TAK-915 did not affect the expression of either SP or Enk mRNA even at $100 \mathrm{mg} / \mathrm{kg}$ (Fig. 6C). Additionally, we examined whether TAK-915 causes side effects of antipsychotic medication such as hyperprolactinemia, hyperglycemia, or

Wilcoxon's test), ${ }^{\dagger} P \leq 0.05,{ }^{\dagger} P \leq 0.01$ (vs. vehicle-MK-801 by two-tailed Wilcoxon's test). 


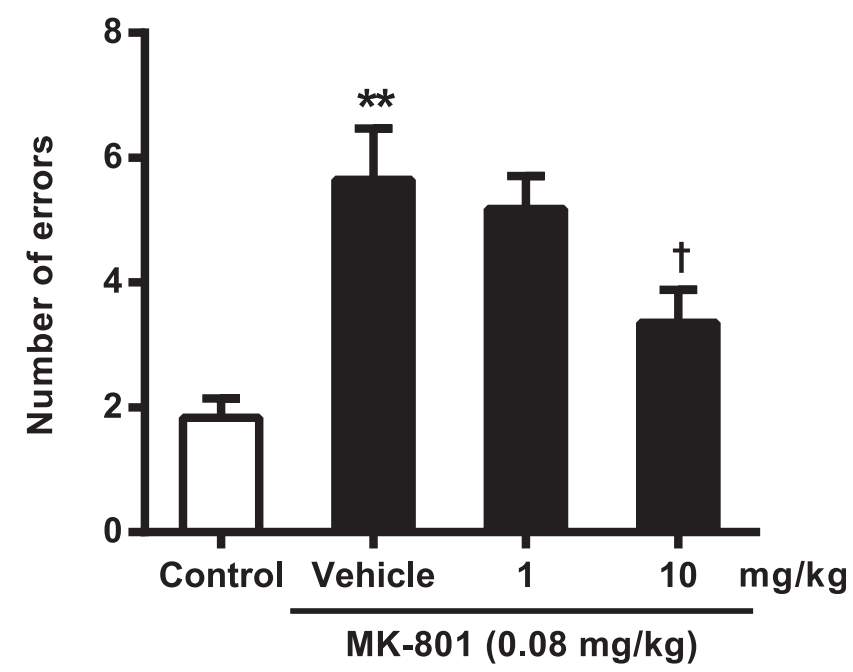

Fig. 4. Effects of TAK-915 on MK-801-induced working memory deficits in the radial arm maze task in rats. Vehicle or TAK-915 $(1$ or $10 \mathrm{mg} / \mathrm{kg}$, p.o.) was administered 2 hours prior to testing and saline or MK-801 $(0.08 \mathrm{mg} / \mathrm{kg}$, s.c. $)$ was administered 0.5 hours prior to testing. The numbers of errors are expressed as mean + S.E.M., $n=6$ for control group, $n=17$ for other groups. ${ }^{* *} P \leq 0.01$ (vs. control by Aspin-Welch test), ${ }^{\dagger} P \leq 0.05$ (vs. vehicle-MK-801 by two-tailed Williams' test).

cataleptic response. TAK-915 did not increase prolactin (Supplemental Fig. 2A) or glucose levels (Supplemental Fig. 2B) in the rat plasma even at $100 \mathrm{mg} / \mathrm{kg}$. Cataleptic response was assessed by the bar test at 2 hours following administration of TAK-915. TAK915 at 10 and $100 \mathrm{mg} / \mathrm{kg}$ did not significantly increase cataleptic response in this test (Supplemental Fig. 3).

\section{Discussion}

In the present study, we showed that TAK-915 works as a brain-penetrant PDE2A inhibitor in vivo. Significant increases in cGMP levels in hippocampus were observed at 3 and $10 \mathrm{mg} / \mathrm{kg}$ of TAK-915 (Fig. 1B). The PDE2A occupancy levels of TAK-915 in the hippocampus at 3 and $10 \mathrm{mg} / \mathrm{kg}$ were $46.6 \%$ and $63.0 \%$, respectively (Ito Y, Imada H, Obayashi Y, Kasahara M, Hattori M, Miyamoto M, Mikami S, Taniguchi T, and Iwashita H, manuscript in preparation). These results suggest that more than $45 \%$ occupancy of PDE2A by TAK-915 would be sufficient to produce a significant increase in cGMP levels in the hippocampus. In contrast, TAK-915 did not affect cAMP levels in the brain under our experimental conditions (Fig. 1). There is a possibility that we could not detect a significant effect on cAMP levels by TAK-915 because of the high baseline for cAMP contents in brain tissues (Fig. 1). However, these observations are in accordance with previous reports that PDE2A inhibition mainly influences cGMP levels rather than cAMP levels (Suvarna and O'Donnell, 2002; Boess et al., 2004). Additionally, TAK-915 dose dependently increased cGMP levels in rat primary neurons, whereas a significant change of cAMP levels was not observed (Supplemental Fig. 4). These findings suggest that PDE2A plays an important role in degrading cGMP levels in the brain, although PDE2A can hydrolyze both cAMP and cGMP. Other PDE family members with higher affinities for cAMP such as PDE4 and PDE10 might be responsible for degrading cAMP in the brain.

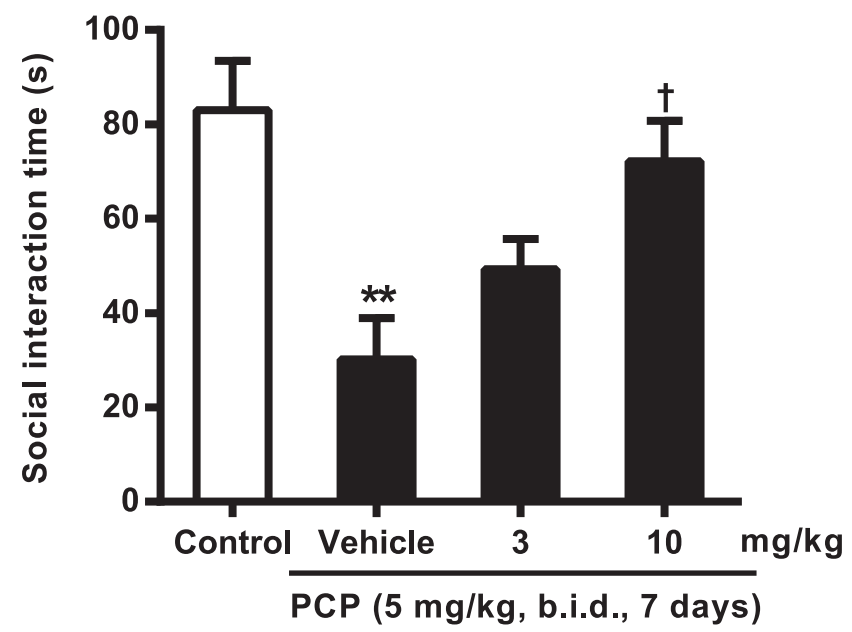

Fig. 5. Effects of TAK-915 on subchronic phencyclidine-induced social withdrawal in the social interaction test in rats. Saline or phencyclidine (PCP, $5 \mathrm{mg} / \mathrm{kg}$, i.p.) was administered twice daily (b.i.d.) from day 1 to day 7 . After an 8-day wash-out period, vehicle or TAK-915 (3 or $10 \mathrm{mg} / \mathrm{kg}$, p.o.) was administered 2 hours before testing. Time spent in active nonaggressive social behavior during the 10-minute session of the test was recorded. Data are expressed as means + S.E.M., $n=12$ per each group. ${ }^{* *} P \leq 0.01$ (vs. control group by Student's $t$ test), ${ }^{\dagger} P \leq 0.05$ (vs. vehicle-PCP by two-tailed Williams' test).

Cyclic AMP and cGMP are differentially involved in distinct phases of memory processing, such as acquisition and consolidation (Bernabeu et al., 1996; Rutten et al., 2007; Bollen et al., 2014; Akkerman et al., 2016; Lueptow et al., 2016). Cyclic GMP-PKG signaling mediates acquisition and early consolidation, whereas cAMP-PKA signaling mediates acquisition and late consolidation. In the passive avoidance task, oral administration of TAK-915 at 2 hours prior to acquisition trial attenuated MK-801-induced episodic memory deficits (Fig. 3). As TAK-915 increased cGMP levels in the rat brain at 2 hours after administration (Fig. 1), the enhancement of memory acquisition mediated by cGMP could contribute to the improvement of episodic memory observed in retention trial. Additionally, it has been reported that cGMP-PKG signaling mediates early consolidation, and late consolidation requires cAMP-PKA signaling (Bollen et al., 2014). Taking into account the pharmacokinetic profile of TAK-915, it is possible that TAK-915 affects not only early consolidation mediated by cGMP-PKG signaling but also late consolidation mediated by cAMP-PKA signaling. Further experiments would be required to investigate the effects of TAK-915 on cyclic nucleotides during behavior tasks and to clarify the temporal contribution of cyclic nucleotides on memory formation.

Cyclic nucleotides play important roles in regulating various signal cascades, including the NMDA receptor pathway, which are involved in such synaptic plasticity as long-term potentiation (Kleppisch and Feil, 2009). The hippocampal synaptic plasticity is known to be a key element of the neurobiological bases of cognitive function (Akhondzadeh, 1999). Elevated cAMP and/or cGMP lead to activation of several sequential cascades that phosphorylate target proteins (Lucas et al., 2000; Esteban et al., 2003; Kleppisch and Feil, 2009). Phosphorylation of GluR1 at serine 845 has been linked to AMPA receptor trafficking to the plasma membrane, which is thought to influence synaptic plasticity and cognition (Derkach et al., 2007; Serulle et al., 2007; Shepherd and 




B

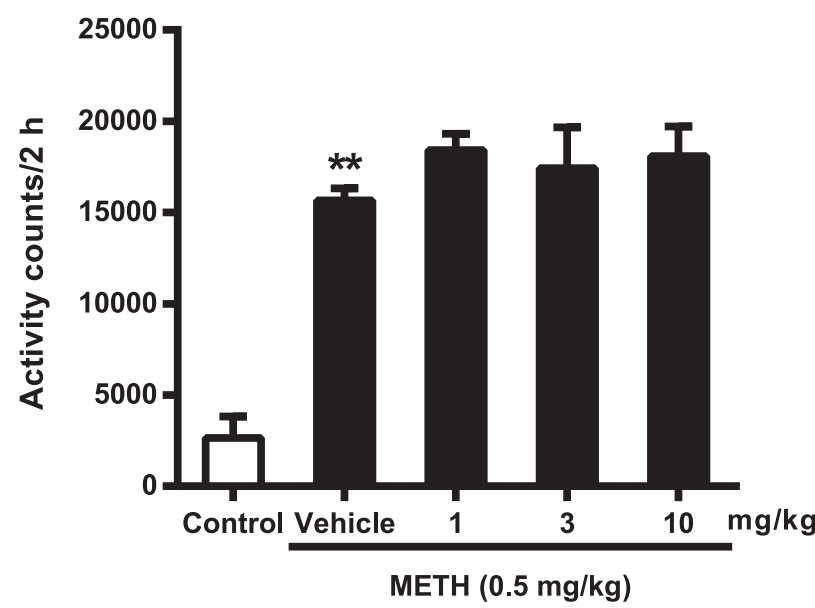

C

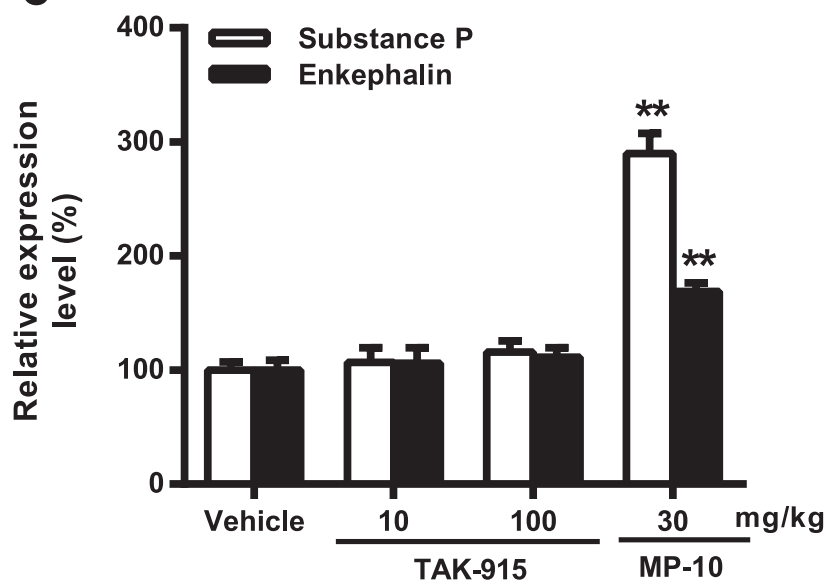

Fig. 6. Effects of TAK-915 on MK-801- or METH-induced hyperlocomotion, and on activation of direct and indirect pathway medium spiny neurons in rats. (A and B) Effects of TAK-915 on MK-801 (A) or methamphetamine (METH) (B) induced hyperlocomotion in rats. Vehicle or TAK-915 $(1,3$, or $10 \mathrm{mg} / \mathrm{kg}$, p.o. $)$ was administered 2 hours before the administration of MK- $801(0.3 \mathrm{mg} / \mathrm{kg}$, s.c.) or METH $(0.5 \mathrm{mg} / \mathrm{kg}$, s.c.). Activity counts during the 2 hours following the administration of MK-801 or METH were calculated. Data are expressed as mean + S.E.M., $n=3$ for control, $n=6$ for $1 \mathrm{mg} / \mathrm{kg}, n=7$ for other groups. $* * P \leq 0.01$ (vs. control by Student's $t$ test). (C) Vehicle, TAK-915 (10 or $100 \mathrm{mg} / \mathrm{kg}$, p.o.), or MP-10 $(30 \mathrm{mg} / \mathrm{kg}$, p.o.) was administered 3 hours before sampling. The rat striatal
Huganir, 2007; Citri and Malenka, 2008). Synaptic GluR1 delivery in the hippocampus has been reported to be required for the hippocampus-dependent learning in the passive avoidance task (Mitsushima et al., 2011). We investigated the effect of TAK-915 in the hippocampal pGluR1 levels associated with activation of downstream pathway of cyclic nucleotide signaling. TAK-915 at $10 \mathrm{mg} / \mathrm{kg}$ significantly increased hippocampal pGluR1 in rats (Fig. 2), indicating that TAK-915 activates the downstream pathway of cyclic nucleotide signaling in the hippocampus. The increased levels of pGluR1 by TAK-915 could enhance cognitive function via modulation of synaptic plasticity.

Among several cognitive domains that are commonly disrupted in schizophrenia, deficits in episodic memory have shown some of the largest effect size (Schaefer et al., 2013). Deficits in spatial working memory also have been consistently reported in schizophrenia patients (Piskulic et al., 2007) and emphasized as one of the key impairments in schizophrenia by the Measurement and Treatment Research to Improve Cognition in Schizophrenia (MATRICS) initiative (Marder and Fenton, 2004). To explore the potential of TAK-915 on episodic memory and spatial working memory, we investigated the effects of TAK-915 on the performance of the passive avoidance task and radial arm maze task in MK-801-treated rats. In both tasks, TAK-915 attenuated memory deficits induced by MK-801 (Figs. 3 and 4). On the basis of in vitro autoradiography studies with rat brain slices, $\left[{ }^{3} \mathrm{H}\right] \mathrm{TAK}-915$ accumulated to high levels in CA3 mossy fibers and subiculum, a structure located between the hippocampus proper and entorhinal cortex (Ito Y, Imada H, Obayashi Y, Kasahara M, Hattori M, Miyamoto M, Mikami S, Taniguchi T, and Iwashita $\mathrm{H}$, manuscript in preparation). These brain regions play pivotal roles in spatial and episodic information processing (O’Mara et al., 2009; Cerasti and Treves, 2010). In addition, TAK-915 significantly induced c-Fos protein expression, a marker of neuronal activity, in the subiculum and entorhinal cortex (Ito Y, Imada H, Obayashi Y, Kasahara M, Hattori M, Miyamoto M, Mikami S, Taniguchi T, and Iwashita $\mathrm{H}$, manuscript in preparation). These results suggest that the procognitive activities of TAK-915 in the passive avoidance task and radial arm maze task might be associated with neuronal activation in these brain regions.

Social withdrawal is one of the key components of negative symptoms in schizophrenia that generally persists through the course of the illness and contributes to poor psychosocial functioning (Pogue-Geile and Harrow, 1985; Morrison and Bellack, 1987; Puig et al., 2008). To investigate the potential for the efficacy of TAK-915 in social withdrawal, we used a subchronic PCP model. PCP is known to produce schizophrenia-like symptoms in humans (Allen and Young, 1978; Morris et al., 2005), and social interaction deficits produced by subchronic treatment with PCP in rodents resemble the negative symptoms, particularly social withdrawal (Jenkins et al., 2008; Neill et al., 2014). As shown in

mRNA expression levels of substance $\mathrm{P}$ (SP, a direct pathway marker) and enkephalin (Enk, an indirect pathway marker) were analyzed using gene expression assays. Data are expressed as mean + S.E.M., $n=4$ for MP-10 treated group, $n=6$ for other groups, ${ }^{* * P} \leq 0.01$ (vs. vehicle by Student's $t$ test). 
Fig. 5, subchronic PCP treatment (5 mg/kg, i.p., twice daily for 7 days) to rats significantly reduced the time spent in social interaction followed by at least an 8-day washout, indicating that this treatment may cause abnormalities in neural system and/or structures associated with social behaviors. TAK-915 at $10 \mathrm{mg} / \mathrm{kg}$ significantly attenuated this reduction of time spent in social interaction (Fig. 5). These results suggest that TAK-915 prevents social withdrawal in the subchronic PCP model relevant to schizophrenia.

Currently used clinical antipsychotic drugs with dopamine $\mathrm{D}_{2}$ blockade such as haloperidol lead to an activation of the indirect pathway in the striatal MSNs, which is thought to be the mechanism of their antipsychotic effects (Kapur and Mamo, 2003; Agid et al., 2008; Kehler and Nielsen, 2011; Suzuki et al., 2015). TAK-915 did not affect MK-801- or METH-induced hyperlocomotion, even at doses that produced a significant increase in cGMP levels in the striatum (Fig. 6, A and B), and did not activate either direct or indirect pathway MSNs in the striatum (Fig. 6C). Our findings coincide with the observation that a PDE2A inhibitor, Lu AF64280, did not produce antipsychotic-like effects in PCP-induced hyperlocomotion in mice, or in the conditioned avoidance response in rats (Redrobe et al., 2014). In contrast to PDE2A inhibitors, a PDE10A inhibitor, MP-10, which showed antipsychotic-like effects in rodents (Grauer et al., 2009), activated both direct and indirect pathway MSNs in the striatum (Fig. 6C). Behavioral outcomes of PDE2A inhibition are different from those of PDE10A inhibition, although PDE2A, as well as PDE10A, is highly expressed in striatal MSNs, and its inhibition increases cGMP levels in the striatum. As the cyclic nucleotides and their appropriate PDEs are confined to distinct cellular compartments (Francis et al., 2011), the specific PDEs may be regulating the distinct pools of cyclic nucleotides and different roles in the striatal MSNs.

Although the mechanism by which TAK-915 attenuates cognitive impairments and social withdrawal induced by NMDA receptor antagonists is still unclear, our findings suggest that TAK-915 provides a strategy for ameliorating these behavioral deficits through upregulation of cyclic nucleotides, mainly cGMP. Previous studies suggest that PDE2A inhibition can enhance the NMDA receptor/NO/cGMP pathway (Suvarna and O'Donnell, 2002; Boess et al., 2004). TAK915 attenuated cognitive deficits and social withdrawal in rats at similar dosage that upregulated cGMP and pGluR1 levels in the rat brain. In line with this, Lu AF64280 also increased cGMP levels in the hippocampus, and attenuated cognitive deficits in animal models of schizophrenia (Redrobe et al., 2014). These findings support the potential of PDE2A inhibitors to impact cognitive function and social behavior through modulation of the NMDA receptor/NO/cGMP pathway in the forebrain. A single infusion of sodium nitroprusside, which augments the levels of NO, a key molecule downstream of the NMDA receptor, significantly improved multiple symptoms of schizophrenia, with effects that lasted for up to 4 weeks (Hallak et al., 2013). These findings support the hypothesis that the modulation of the cGMP signaling pathway by TAK915 may provide beneficial clinical effects in schizophrenia.

In conclusion, TAK-915 ameliorates cognitive impairments and social withdrawal induced by NMDA receptor antagonists in rodents. This selective PDE2A inhibitor has therapeutic potential for cognitive impairments and negative symptoms in schizophrenia.

\section{Acknowledgments}

The authors acknowledge Dr. Keisuke Hirai, Dr. Haruhide Kimura, Dr. Deborah Hartman, and Dr. Kazunori Suzuki for reading our manuscript and providing valuable comments.

\section{Authorship Contributions}

Participated in research design: Nakashima, Iwashita.

Conducted experiments: Nakashima, Ito, Imada, Shiraishi, Suzuki, Miyamoto, Taniguchi.

Performed data analysis: Nakashima, Ito, Imada, Shiraishi, Suzuki, Miyamoto, Taniguchi.

Wrote or contributed to the writing of the manuscript: Nakashima, Iwashita.

\section{References}

Agid O, Kapur S, and Remington G (2008) Emerging drugs for schizophrenia. Expert Opin Emerg Drugs 13:479-495.

Akhondzadeh S (1999) Hippocampal synaptic plasticity and cognition. J Clin Pharm Ther 24:241-248.

Akkerman S, Blokland A, and Prickaerts J (2016) Possible overlapping time frames of acquisition and consolidation phases in object memory processes: a pharmacological approach. Learn Mem 23:29-37.

Allen RM and Young SJ (1978) Phencyclidine-induced psychosis. Am J Psychiatry 135:1081-1084.

Andine P, Widermark N, Axelsson R, Nyberg G, Olofsson U, Martensson E, and Sandberg M (1999) Characterization of MK-801-induced behavior as a putative rat model of psychosis. J Pharmacol Exp Ther 290:1393-1408.

Bernabeu R, Schmitz P, Faillace MP, Izquierdo I, and Medina JH (1996) Hippocampal cGMP and cAMP are differentially involved in memory processing of inhibitory avoidance learning. Neuroreport 7:585-588.

Boess FG, Hendrix M, van der Staay FJ, Erb C, Schreiber R, van Staveren W, de Vente J, Prickaerts J, Blokland A, and Koenig G (2004) Inhibition of phosphodiesterase 2 increases neuronal cGMP, synaptic plasticity and memory performance. Neuropharmacology 47:1081-1092.

Bollen E, Akkerman S, Puzzo D, Gulisano W, Palmeri A, D’Hooge R, Balschun D, Steinbusch HW, Blokland A, and Prickaerts J (2015) Object memory enhancement by combining sub-efficacious doses of specific phosphodiesterase inhibitors. Neuropharmacology 95:361-366.

Bollen E, Puzzo D, Rutten K, Privitera L, De Vry J, Vanmierlo T, Kenis G, Palmeri A D'Hooge R, Balschun D, et al. (2014) Improved long-term memory via enhancing cGMP-PKG signaling requires cAMP-PKA signaling. Neuropsychopharmacology 39:2497-2505.

Cayre E, Parachou D, Meot B, Rion B, Drieu Lau Rochelle C, Sheardown M, Ruprah P, Walsh L, Reeves J, Fosbeary R, et al. (2016) Characterization of PGM039678, a positive allosteric modulator of the muscarinic M4 receptor, in animal models of schizophrenia, presented at Neuroscience 2016; Nov. 12-16; San Diego, CA. Society for Neuroscience, Washington, D.C.

Cerasti E and Treves A (2010) How informative are spatial CA3 representations established by the dentate gyrus? PLOS Comput Biol 6:e1000759.

Citri A and Malenka RC (2008) Synaptic plasticity: multiple forms, functions, and mechanisms. Neuropsychopharmacology 33:18-41.

Coyle JT (1996) The glutamatergic dysfunction hypothesis for schizophrenia. Harv Rev Psychiatry 3:241-253.

Derkach VA, Oh MC, Guire ES, and Soderling TR (2007) Regulatory mechanisms of AMPA receptors in synaptic plasticity. Nat Rev Neurosci 8:101-113.

Esteban JA, Shi SH, Wilson C, Nuriya M, Huganir RL, and Malinow R (2003) PKA phosphorylation of AMPA receptor subunits controls synaptic trafficking underlying plasticity. Nat Neurosci 6:136-143.

Foussias G, Agid O, Fervaha G, and Remington G (2014) Negative symptoms of schizophrenia: clinical features, relevance to real world functioning and specificity versus other CNS disorders. Eur Neuropsychopharmacol 24:693-709.

Francis SH, Blount MA, and Corbin JD (2011) Mammalian cyclic nucleotide phosphodiesterases: molecular mechanisms and physiological functions. Physiol Rev 91: 651-690.

Goff DC and Coyle JT (2001) The emerging role of glutamate in the pathophysiology and treatment of schizophrenia. Am J Psychiatry 158:1367-1377.

Grauer SM, Pulito VL, Navarra RL, Kelly MP, Kelley C, Graf R, Langen B, Logue S, Brennan J, Jiang L, et al. (2009) Phosphodiesterase 10A inhibitor activity in preclinical models of the positive, cognitive, and negative symptoms of schizophrenia. $J$ Pharmacol Exp Ther 331:574-590.

Hallak JE, Maia-de-Oliveira JP, Abrao J, Evora PR, Zuardi AW, Crippa JA, Belmonte-de-Abreu P, Baker GB, and Dursun SM (2013) Rapid improvement of acute schizophrenia symptoms after intravenous sodium nitroprusside: a randomized, double-blind, placebo-controlled trial. JAMA Psychiatry 70:668-676.

Javitt DC and Zukin SR (1991) Recent advances in the phencyclidine model of schizophrenia. Am J Psychiatry 148:1301-1308.

Jenkins TA, Harte MK, McKibben CE, Elliott JJ, and Reynolds GP (2008) Disturbances in social interaction occur along with pathophysiological deficits following sub-chronic phencyclidine administration in the rat. Behav Brain Res 194:230-235.

Jones CA, Watson DJ, and Fone KC (2011) Animal models of schizophrenia. Br J Pharmacol 164:1162-1194.

Kapur S and Mamo D (2003) Half a century of antipsychotics and still a central role for dopamine D2 receptors. Prog Neuropsychopharmacol Biol Psychiatry 27:1081-1090.

Kehler J and Nielsen J (2011) PDE10A inhibitors: novel therapeutic drugs for schizophrenia. Curr Pharm Des 17:137-150. 
Kleppisch T and Feil R (2009) cGMP signalling in the mammalian brain: role in synaptic plasticity and behaviour. Handb Exp Pharmacol 191:549-579.

Lee BH and Kim YK (2008) Reduced plasma nitric oxide metabolites before and after antipsychotic treatment in patients with schizophrenia compared to controls. Schizophr Res 104:36-43.

Lin CH, Lane HY, and Tsai GE (2012) Glutamate signaling in the pathophysiology and therapy of schizophrenia. Pharmacol Biochem Behav 100:665-677.

Lucas KA, Pitari GM, Kazerounian S, Ruiz-Stewart I, Park J, Schulz S, Chepenik $\mathrm{KP}$, and Waldman SA (2000) Guanylyl cyclases and signaling by cyclic GMP Pharmacol Rev 52:375-414.

Lueptow LM, Zhan CG, and O'Donnell JM (2016) Cyclic GMP-mediated memory enhancement in the object recognition test by inhibitors of phosphodiesterase- 2 in mice. Psychopharmacology (Berl) 233:447-456.

Marder SR and Fenton W (2004) Measurement and treatment research to improve cognition in schizophrenia: NIMH MATRICS initiative to support the development of agents for improving cognition in schizophrenia. Schizophr Res 72:5-9.

Meador-Woodruff JH and Healy DJ (2000) Glutamate receptor expression in schizophrenic brain. Brain Res Brain Res Rev 31:288-294.

Messinger JW, Tremeau F, Antonius D, Mendelsohn E, Prudent V, Stanford AD and Malaspina D (2011) Avolition and expressive deficits capture negative symptom phenomenology: implications for DSM-5 and schizophrenia research. Clin Psychol Rev 31:161-168.

Mikami S, Nakamura S, Ashizawa T, Nomura I, Kawasaki M, Sasaki S, Oki H, Kokubo H, Hoffman ID, Zou H, et al. (2017) Discovery of clinical candidate N-((1S) 1-(3-fluoro-4-(trifluoromethoxy)phenyl)-2-methoxyethyl)-7-methoxy-2-oxo-2,3dihydropyrido[2,3-b]pyrazine-4(1H)-carboxamide (TAK-915): a highly potent, selective, and brain-penetrating phosphodiesterase $2 \mathrm{~A}$ inhibitor for the treatment of cognitive disorders. J Med Chem 60:7677-7702.

Mitsushima D, Ishihara K, Sano A, Kessels HW, and Takahashi T (2011) Contextual learning requires synaptic AMPA receptor delivery in the hippocampus. Proc Natl Acad Sci USA 108:12503-12508.

Morris BJ, Cochran SM, and Pratt JA (2005) PCP: from pharmacology to modelling schizophrenia. Curr Opin Pharmacol 5:101-106.

Morrison RL and Bellack AS (1987) Social functioning of schizophrenic patients: clinical and research issues. Schizophr Bull 13:715-725.

Nakano Y, Yoshimura R, Nakano H, Ikenouchi-Sugita A, Hori H, Umene-Nakano W, Ueda N, and Nakamura J (2010) Association between plasma nitric oxide metabolites levels and negative symptoms of schizophrenia: a pilot study. Hum Psychopharmacol 25:139-144.

Neill JC, Barnes S, Cook S, Grayson B, Idris NF, McLean SL, Snigdha S, Rajagopal L, and Harte MK (2010) Animal models of cognitive dysfunction and negative symptoms of schizophrenia: focus on NMDA receptor antagonism. Pharmacol Ther 128:419-432.

Neill JC, Harte MK, Haddad PM, Lydall ES, and Dwyer DM (2014) Acute and chronic effects of NMDA receptor antagonists in rodents, relevance to negative symptoms of schizophrenia: a translational link to humans. Eur Neuropsychopharmacol 24:822-835.

Nishiyama K, Suzuki H, Harasawa T, Suzuki N, Kurimoto E, Kawai T, Maruyama M, Komatsu H, Sakuma K, Shimizu Y, et al. (2017) FTBMT, a novel and selective GPR52 agonist, demonstrates antipsychotic-like and procognitive effects in rodents, revealing a potential therapeutic agent for schizophrenia. J Pharmacol Exp Ther 363:253-264.

Olney JW and Farber NB (1995) Glutamate receptor dysfunction and schizophrenia. Arch Gen Psychiatry 52:998-1007.

O'Mara SM, Sanchez-Vives MV, Brotons-Mas JR, and O'Hare E (2009) Roles for the subiculum in spatial information processing, memory, motivation and the temporal control of behaviour. Prog Neuropsychopharmacol Biol Psychiatry 33:782-790. Piskulic D, Olver JS, Norman TR, and Maruff P (2007) Behavioural studies of spatial working memory dysfunction in schizophrenia: a quantitative literature review. Psychiatry Res 150:111-121.

Pogue-Geile MF and Harrow M (1985) Negative symptoms in schizophrenia: their longitudinal course and prognostic importance. Schizophr Bull 11:427-439.

Puig O, Penades R, Gasto C, Catalan R, Torres A, and Salamero M (2008) Verbal memory, negative symptomatology and prediction of psychosocial functioning in schizophrenia. Psychiatry Res 158:11-17.

Redrobe JP, Jorgensen M, Christoffersen CT, Montezinho LP, Bastlund JF, Carnerup M, Bundgaard C, Lerdrup L, and Plath N (2014) In vitro and in vivo char acterisation of Lu AF64280, a novel, brain penetrant phosphodiesterase (PDE) 2A inhibitor: potential relevance to cognitive deficits in schizophrenia. Psychophar macology (Berl) 231:3151-3167.
Reneerkens OA, Rutten K, Bollen E, Hage T, Blokland A, Steinbusch HW, and Prickaerts J (2013) Inhibition of phoshodiesterase type 2 or type 10 reverses object memory deficits induced by scopolamine or MK-801. Behav Brain Res 236: $16-22$

Rutten K, Prickaerts J, Hendrix M, van der Staay FJ, Sik A, and Blokland A (2007) Time-dependent involvement of cAMP and cGMP in consolidation of object memory: studies using selective phosphodiesterase type 2, 4 and 5 inhibitors. Eur $J$ Pharmacol 558:107-112.

Schaefer J, Giangrande E, Weinberger DR, and Dickinson D (2013) The global cognitive impairment in schizophrenia: consistent over decades and around the world Schizophr Res 150:42-50.

Serulle Y, Arancio O, and Ziff EB (2008) A role for cGMP-dependent protein kinase II in AMPA receptor trafficking and synaptic plasticity. Channels (Austin) 2: $230-232$

Serulle Y, Zhang S, Ninan I, Puzzo D, McCarthy M, Khatri L, Arancio O, and Ziff EB (2007) A GluR1-cGKII interaction regulates AMPA receptor trafficking. Neuron 56: $670-688$.

Shamsi S, Lau A, Lencz T, Burdick KE, DeRosse P, Brenner R, Lindenmayer JP, and Malhotra AK (2011) Cognitive and symptomatic predictors of functional disability in schizophrenia. Schizophr Res 126:257-264.

Shepherd JD and Huganir RL (2007) The cell biology of synaptic plasticity: AMPA receptor trafficking. Annu Rev Cell Dev Biol 23:613-643.

Shiraishi E, Suzuki K, Harada A, Suzuki N, and Kimura H (2016) The phosphodiesterase $10 \mathrm{~A}$ selective inhibitor TAK-063 improves cognitive functions associated with schizophrenia in rodent models. J Pharmacol Exp Ther 356: $587-595$

Stephenson DT, Coskran TM, Kelly MP, Kleiman RJ, Morton D, O’Neill SM, Schmidt CJ, Weinberg RJ, and Menniti FS (2012) The distribution of phosphodiesterase 2A in the rat brain. Neuroscience 226:145-155.

Stephenson DT, Coskran TM, Wilhelms MB, Adamowicz WO, O’Donnell MM, Muravnick KB, Menniti FS, Kleiman RJ, and Morton D (2009) Immunohistochemical localization of phosphodiesterase $2 \mathrm{~A}$ in multiple mammalian species. J Histochem Cytochem 57:933-949.

Suvarna NU and O'Donnell JM (2002) Hydrolysis of N-methyl-D-aspartate receptorstimulated cAMP and cGMP by PDE 4 and PDE2 phosphodiesterases in primary neuronal cultures of rat cerebral cortex and hippocampus. J Pharmacol Exp Ther 302:249-256.

Suzuki K, Harada A, Shiraishi E, and Kimura H (2015) In vivo pharmacological characterization of TAK-063, a potent and selective phosphodiesterase $10 \mathrm{~A}$ inhibitor with antipsychotic-like activity in rodents. $J$ Pharmacol Exp Ther 352: $471-479$

Suzuki K, Harada A, Suzuki H, Miyamoto M, and Kimura H (2016) TAK-063, a PDE10A inhibitor with balanced activation of direct and indirect pathways, provides potent antipsychotic-like effects in multiple paradigms. Neuropsychopharmacology 41:2252-2262.

Torgalsboen AK, Mohn C, Czajkowski N, and Rund BR (2015) Relationship between neurocognition and functional recovery in first-episode schizophrenia: results from the second year of the Oslo multi-follow-up study. Psychiatry Res 227:185-191.

van der Staay FJ, Rutten K, Erb C, and Blokland A (2011) Effects of the cognition impairer MK-801 on learning and memory in mice and rats. Behav Brain Res 220: $215-229$.

Verhoest PR, Chapin DS, Corman M, Fonseca K, Harms JF, Hou X, Marr ES, Menniti FS, Nelson F, O'Connor R, et al. (2009) Discovery of a novel class of phosphodiesterase 10A inhibitors and identification of clinical candidate 2-[4-(1methyl-4-pyridin-4-yl-1H-pyrazol-3-yl)-phenoxymethyl]-quinoline (PF-2545920) for the treatment of schizophrenia. J Med Chem 52:5188-5196.

Wang JQ, Arora A, Yang L, Parelkar NK, Zhang G, Liu X, Choe ES, and Mao L (2005) Phosphorylation of AMPA receptors: mechanisms and synaptic plasticity. Mol Neurobiol 32:237-249.

Wilson CA and Koenig JI (2014) Social interaction and social withdrawal in rodents as readouts for investigating the negative symptoms of schizophrenia. Eur Neuropsychopharmacol 24:759-773.

Address correspondence to: Dr. Hiroki Iwashita, Neuroscience Drug Discovery Unit, Research, Takeda Pharmaceutical Company Limited, 26-1, Muraoka-higashi 2-chome, Fujisawa, Kanagawa 251-8555, Japan. E-mail: hiroki.iwashita@takeda.com 